\title{
How vulnerable is risk aversion to wealth, health and other risks? An empirical analysis for Europe
}

\author{
Christophe Courbage $^{* a}$, Guillem Montoliu-Montes ${ }^{\mathrm{a}, \mathrm{b}}$, Béatrice Rey ${ }^{\mathrm{c}}$ \\ ${ }^{\text {a }}$ Geneva School of Business Administration (HES-SO), Switzerland \\ ${ }^{\mathrm{b}}$ University of Lausanne, Department of Actuarial Science, Switzerland \\ ${ }^{\mathrm{c}}$ Université de Lyon, CNRS, GATE Lyon Saint-Etienne, France
}

\begin{abstract}
This paper empirically assesses how financial risk aversion reacts to a change in individuals' wealth and health and to the introduction of both financial and health risks using the Survey of Health, Ageing, and Retirement in Europe (SHARE). Individuals in our sample exhibit financial risk aversion decreasing both in wealth and health. Financial risk aversion is also found to increase in the presence of both background financial and health risks. Interestingly, the sensitivity of financial risk aversion to wealth, respectively to health, is shown to depend on the presence of a financial background risk, respectively health background risk, but in opposite directions. Such findings can help to better understand various economic decisions in a risky environment.
\end{abstract}

Keywords: risk aversion, (cross-) DARA, (cross-) risk vulnerability, background risk, health risk.

JEL classification: D01, D81, I12

\section{Introduction}

Risk aversion behaviours drive many economic decisions, whether this is related to insurance, investment, portfolio allocation, health care, housing, etc. The concept of risk aversion has therefore benefitted from an extended literature both theoretically and empirically.

The literature of risk aversion stems from the seminal works of Arrow (1965) and Pratt (1964) who defined risk aversion as a preference for a certain event over a random event. Risk aversion has been shown to be influenced by various parameters amongst which individual's wealth, individual's health and the presence of other risks faced by individuals. Arrow (1970) was the first to make the assumption of risk aversion decreasing in wealth, also known as decreasing absolute risk aversion (DARA). Other works, e.g. Malevergne and Rey (2009), made reference to the concept of cross-DARA, i.e. risk aversion to wealth decreasing with individual's health. While DARA and cross-DARA deal with how vulnerable risk aversion is to a loss of wealth or health, another strand of literature investigated how risk aversion towards financial risk is vulnerable to the presence of another risk, i.e. a background risk, being either financial or non-financial. This has given rise to the concept of risk vulnerability (Gollier and Pratt, 1996) and cross-risk vulnerability (Malevergne and Rey, 2009), respectively. DARA and risk vulnerability, and cross-DARA and cross risk vulnerability, are theoretically linked to each other in the sense that, under the expected utility framework, (cross-) DARA is a necessary condition for (cross-) risk vulnerability. Knowing how risk aversion reacts to a loss of wealth and health, or to a riskier environment, can offer some valuable information on how various economic decisions can be impacted by external shocks on wealth and health.

\footnotetext{
* Corresponding author. Email: christophe.courbage@hesge.ch
} 
The aim of this paper is to test empirically whether individuals exhibit DARA, cross-DARA, risk vulnerability and cross-risk vulnerability, using the SHARE (Survey of Health, Ageing, and Retirement in Europe) database which deals with the health, lifestyle and financial situation of individuals aged 50 years and over in the majority of European countries. While the DARA hypothesis has been empirically studied rather extensively, few papers have investigated the three other hypotheses. When they did, they often indirectly tested risk aversion through the composition of a financial portfolio in terms of risky assets, they did consider specific background risks or they considered these hypothesis separately. Contrary to most works on the topic, this paper takes advantage of a specific question in SHARE that makes it possible to measure directly risk aversion in terms of individual preferences in the spirit of the definition by Arrow (1965) and Pratt (1964). By using the SHARE database, we can also study these four hypothesis altogether and then investigate the links that exist amongst themselves.

This paper uses various variables to define the level of wealth, the level of health as well as wealth and health risks so as to take into account potential endogeneity concerns regarding risk aversion. In particular, we once again take advantage of the SHARE database that makes it possible to define precise measures of wealth and health status as well as of financial and health risks.

Our results show that, indeed, individuals exhibit DARA and cross-DARA, i.e. financial risk aversion decreases in wealth and health, and also risk vulnerability and cross-risk vulnerability, i.e. financial risk aversion increases with the presence of background financial and health risks. Additionally, we find that the DARA effect is lower in the presence of a financial background risk while the cross-DARA effect is higher in the presence of a health background risk. Hence, for an individual facing a financial background risk, an increase in wealth will reduce his/her level of risk aversion but to a much lower extent than without background risk. While, for an individual facing a background health risk, an increase in health will reduce his/her level of financial risk aversion but to a much higher extent than without background risk. Interestingly, these results are equivalent to have the intensity of risk vulnerability increasing with the level of wealth and the intensity of cross-risk vulnerability decreasing in health. These findings can therefore shed light on how various economic decisions under risk should be impacted by changes in the external environment of individuals regarding their wealth and health.

The article is organised as follows. In section 2, we briefly summarise the empirical and theoretical literature related to these four hypothesis of risk aversion. Section 3 is devoted to the presentation of the database, the variables used and the econometric strategy. Sections 4 and 5 present and discuss the results with various econometric specifications. Finally, the last section is devoted to some concluding remarks.

\section{Literature review}

According to Arrow (1965) and Pratt (1964), an individual is risk-averse if he always prefers the expected outcome of a lottery with certainty rather than the lottery itself. Risk aversion is then defined as a preference for a certain situation over a risky situation. Arrow (1965) was the first to hypothesise that risk aversion is likely to be decreasing with individual wealth, a hypothesis know as DARA. DARA has been extensively empirically studied. Most empirical works confirm this hypothesis, for instance whether this is for a sample of rice growers on small farms in Nepal (Hamal and Anderson, 1987), for Italy (Guido and Paiella, 2008), or using experiments (Levy, 1994). DARA explains why wealthier people should buy less insurance and invest more in risky assets than people with less wealth. Yet, a few studies have found increasing absolute risk aversion based on life insurance decisions (see e.g. Eisenhauer, 1997). 
Cross-DARA is a much more recent hypothesis and stems from the literature on multivariate risk aversion where preferences depend both on wealth and health. The term cross-DARA was first coined in Malevergne and Rey (2009) as risk aversion to wealth being decreasing in health even if this hypothesis was studied earlier on. Empirically, there is currently a debate on the effects of a deterioration in health on risk aversion. Cross-DARA has been studied mostly in the financial literature in the context of the determinants of individuals' asset allocation without making explicit reference to the term cross-DARA. Rosen and Wu (2004) using American data from the 1992-1998 waves of the Health and Retirement Study (HRS) show that poor health is associated with a smaller share of financial wealth held in risky assets and a larger share in safe assets, therefore supporting the cross-DARA hypothesis. This is confirmed by Cardak and Wilkins (2009) who find that risky asset holding is discouraged by poor health using Australian data. Yet, Smith and Love (2010), using the 1992-2006 waves of the HRS and controlling for unobserved household heterogeneity, find that health does not appear to significantly affect portfolio choice among single households. Fratantoni (1998), using the U.S. 1989 Survey of Consumer Finances, finds that self-perceived health is positively correlated with the share in risky assets. Atella et al. (2012), using the SHARE database, find mixed evidence of crossDARA as they show that worse current perceived health status force households to reduce their exposures to financial risk in their portfolio allocation only in countries with a protective healthcare system. A few other papers directly test cross-DARA (still without making reference to this term) by looking at the effect of health shocks on various measures of risk aversion. Schurer (2015) finds that health shocks significantly increase individual risk aversion using data from waves 2006-2012 of the German Socio-Economic Panel and where risk aversion is measured by self-assessed risk willingness. Decker and Schmitz (2016) find that individuals, after a shock in their health measured as a sharp reduction in their grip strength, declare themselves to be less willing to take risks in general.

Risk vulnerability stems from Gollier and Pratt (1996) and means that risk aversion increases with the presence of an independent unfair background risk. With the expected utility framework, sufficient and necessary conditions on the utility function to have risk vulnerability are quite complex. However, a necessary condition for risk vulnerability is DARA. Empirical studies on risk vulnerability are rather scarce. Once again, most papers use portfolio asset allocation decisions as a measure of risk aversion. Guiso et al. (1996) show that investment in risky financial assets responds negatively to income risk using the 1989 Bank of Italy Survey of Household Income and Wealth and where income risk is defined by the subjective variance of the expected future real income, supporting the risk vulnerability hypothesis. Similar results are found for U.S. data (Haliassos and Bertaut, 1995; Frantatoni, 1998), German data (Hochguertel, 2003) and Australian data (Cardak and Wilkins, 2008). Very few papers define risk aversion in terms of willingness to take risks and not in terms of portfolio allocation decision. The only one we are aware of is Guiso and Paiella (2008). Using a macroeconomic indicator of background risk and defining risk aversion by the willingness to take risks, they find that risk aversion is positively correlated with background risk for Italian households, supporting also the risk vulnerability hypothesis.

Finally, regarding cross-risk vulnerability, this concept was theoretically introduced by Malevergne and Rey (2009). Within the expected utility framework, sufficient and necessary conditions on individual preferences for cross-risk vulnerability are also rather complex. A necessary condition for cross-vulnerability is cross-DARA. Very few papers have tested this hypothesis and they strongly rely on both the definition of health risks and of risk aversion. Edwards (2008) shows that individuals with higher probabilities of medical expenses lower their risky portfolio shares. This is confirmed by Goldman and Maestas (2013) showing that Medicare beneficiaries who face less medical expenditure risk are more likely to hold risky financial assets. Atella et al. (2012) using SHARE data show that health risks, as measured by 
an index taking into account risky behaviour and asymptomatic disease, affect portfolio choices only in countries with less protective healthcare systems.

\section{The data and empirical approach}

\subsection{Data}

SHARE is a multidisciplinary, longitudinal and cross-national micro-database containing information on health-related variables, labour market variables, economic variables and other variables (including education, housing, social support and risk attitudes) of a representative sample of European individuals aged 50 or older and their spouses. A first wave of SHARE was released in 2004. Since then, six other waves of the survey were released. SHARE follows the design of the U.S. Health and Retirement study and the English Longitudinal Study of Ageing. For more details on the survey, readers should refer to Börsch-Supan and Jürges (2005).

For this study, we use the fifth wave of SHARE. It contains information about 66'246 individuals from 15 different countries (Austria, Belgium, Switzerland, Czech Republic, Germany, Denmark, Estonia, Spain, France, Israel, Italy, Luxembourg, Netherlands, Sweden and Slovenia) and the fieldwork was completed in November 2013. Missing values for some variables have left us with 24'281 observations with an average of 1'619 observations per country.

\subsection{The dependent variable: financial risk aversion}

In SHARE, individuals evaluate their financial risk aversion by answering the following question:

When people invest their savings they can choose between assets that give low return with little risk to lose money, for instance a bank account or a safe bond, or assets with a high return but also a higher risk of losing, for instance stocks and shares. Which of the statements on the card comes closest to the amount of financial risk that you are willing to take when you save or make investments?

1. Take substantial financial risks expecting to earn substantial returns

2. Take above average financial risks expecting to earn above average returns

3. Take average financial risks expecting to earn average returns

4. $\quad$ Not willing to take any financial risks

Following Bonsang and Dohmen (2015), Schurer (2015) and Decker and Smith (2016), we use these four answers to measure the intensity of financial risk aversion. Answer 4 being the highest level of risk aversion and answer 1, the lowest. According to Schurer (2015), we assume that risk aversion as defined by these four answers is approximately continuous. This assumption allows us to work with the Ordinary Least Squares (OLS) and the Instrumental Variables (IV) methods.

Most respondents (76\% of the participants) answer item 4. $20 \%$ of the sample answer item $3,3 \%$ answer item 2 and the remaining $1 \%$ answer item 1 . 
As it often happens with self-assessed variables, one could question the reliability of selfreported risk aversion in predicting future real-life behaviour. For instance, are incentives correctly aligned in order to ensure that interviewed people are going to reveal their true preferences? Dohmen et al. (2011) also address this particular issue for risk aversion and conclude that the answers to that kind of question reflect in a reliable way the behaviour of people in a laboratory experiment.

\subsection{Explanatory variables}

\subsubsection{Wealth}

As financial variables used to test DARA, we consider financial wealth, i.e. the amount the respondent has in bank accounts, bonds, stocks, mutual funds and retirement accounts, and annual income, both measured in euros.

Household income is computed as the monthly declared household income multiplied by 12 , plus a 5\% withdrawal of current financial wealth. As we focus on individuals rather than households, we divide household annual income by the number of members in the respondent's household. Finally, we eliminate from the sample all individuals with an income equal or lower than $0 €$, greater than 800 million $€$ or declaring a financial wealth greater than 1 billion $€$.

The sample wealth and income distributions are clearly right-skewed. The sample mean financial wealth is $77^{\prime} 124 €$, and its median equals to 5'000€. Annual income distribution is less skewed, with a mean of 51'905 $€$ and a median of 12'050 $€$. Median wealth and income are larger for those answering items 1, 2 and 3 (20'002 $€$ and 16'140 $€$ respectively) than for those answering item 4 (3'501€ and 10'891 $€$ respectively) to the risk aversion question.

\subsubsection{Health}

We define health status as the individual's perceived health status. This measure is based on the standard self-reported health for which individuals are asked how they would define their health status. In SHARE, the question is:

Would you say your health is:

\section{Excellent}

2. Very good

3. Good

4. Fair

5. Poor

To facilitate the interpretation of the results, we inverse the order of the answers, i.e. with answer 5 being the best one and answer 1 the worst one.

A large proportion of individuals (representing $36 \%$ of the sample) declare themselves to be in good health. A $42 \%$ of the sample declares to be in poor or fair health and the remaining $22 \%$ declares to be in very good or excellent health. 


\subsubsection{Financial background risk}

The empirical definition of a financial background risk is not trivial. Different measures have been used in the literature, with labour income uncertainty being the dominant one. For instance, Guiso et al. (2002) model financial background risk by estimating a distribution function of future income from the perceived probability of job loss, the distribution of future wages and the distribution of unemployment compensation. Cardak and Wilkins (2009) measure financial background risk as the realized variation of the household past labour income controlled with other variables such as the fact of being multiple earners in the household, the occupation and the mortgage over income ratio. Finally, Guiso and Paiella (2008) use a macroeconomic indicator of financial background risk, i.e. the variance of the residuals obtained by regressing the GDP in the province of the surveyed individual on a time trend.

As there is no data at the provincial level available in SHARE, we do not rely on macroeconomic measures. Additionally, such measures might have some problems of endogeneity arising from a possible correlation between risk-aversion and unobserved countryspecific characteristics related to economic development as the countries with the largest variability in the cyclical component of the GDP are also the ones with the lowest GDP per capita in our sample, with the exception of Luxembourg. Instead, we use some of the sources of background risk highlighted by Cardak and Wilkins (2009). We define financial background risk through a binary variable that equals one if the surveyed individual faces one of the following situations:

\section{1- Feels that his job security is poor}

2- Lives alone, and there is no additional people from outside the household contributing to his income

and zero otherwise.

As our sample is basically composed of older individuals, they are not necessarily employed, but can be either retired or unemployed. This is why we also consider, in addition to poor job security, the fact of living alone in our definition of financial background risk. Additionally, we add self-employed, a dummy variable equals 1 if the individual is self-employed and equals zero otherwise, as control variable. This makes it possible to eliminate potential endogeneity issues of the variable measuring financial background risk as some individuals might choose to have an additional level of income risk (in that case job insecurity) precisely because they are less risk-averse.

In our sample, $20 \%$ of individuals face at least one of the situations defined as a background financial risk.

\subsubsection{Health background risk}

Defining a health risk also is not so obvious. Attella et al. (2012), studying the effect of future health risk on the probability of stock holding, define health risk through an index including an average number of risky behaviours (smoking, drinking, sedentary lifestyle), an average number of asymptomatic diseases (high blood pressure, high blood cholesterol and osteoporosis) and grip strength.

However, such a measure of health risk could be potentially biased. Indeed, risky behaviours might be endogenous as financial risk aversion could be correlated with unobserved determinants of risky healthy behaviour. Endogeneity could also affect the number of asymptomatic diseases as this variable is dependent on risky behaviours according to different 
WHO reports (WHO, 2009, 2013) studying the risk factors leading to different diseases such as hypertension or diabetes. In order to avoid these potential endogeneity concerns, we define health risk through the following question in SHARE:

Are you afraid that your health will limit your ability to work in this job, before regular retirement?

This definition of health risk describes an unfair background health risk (a future worsening in health) and is likely to be exogenous if we control it for the behavioural health risk factors.

$12 \%$ of the respondents declare themselves to face a background health risk while the remaining $88 \%$ are not concerned with such situation.

\subsubsection{Interaction terms}

In addition to the previous four explanatory variables, we decided to interact the variables Wealth with Financial Background Risk and Health with Health Background Risk respectively ${ }^{1}$.

The main reason for including those two interaction terms comes from the fact that the effect of wealth or health status on financial risk aversion could be heterogeneous in our sample. Indeed, the presence of a background risk might have an effect on the sensitivity of financial risk aversion to wealth or to health. Indeed, not only the presence of a background risk could impact financial risk aversion but it could also modify the sensitivity of financial risk aversion to wealth and to health.

Equivalently, these interaction terms indicate how the effect of a given background risk on financial risk aversion is affected by the level of wealth (in the case of a financial background risk) and health (in the case of a health background risk), i.e. how risk vulnerability and crossrisk vulnerability are vulnerable to wealth and to health respectively ${ }^{2}$. For example, the presence of a financial (health) background risk, which increases financial risk aversion if individuals are (cross-) risk vulnerable, might cause a larger increase in financial risk aversion for individuals with lower wealth (health).

\subsection{Other controls}

As controls, we include four personal characteristics studied by Dohmen et al. (2011) as plausibly exogenous determinants of risk aversion which are gender (equals to 1 if the respondent is a woman, 0 otherwise), age, height and parental education. Additionally, we include a measure of cognitive ability created from three different tests, i.e. numeracy questions, verbal fluidity and memory following Dohmen and Bonsang (2015) who show that this variable is an important determinant of risk attitudes for old people. As commented before, we include a dummy Self-employed in order to control our measure of background financial risk. We also include two measures of household composition, Married which equals one if the surveyed is married or has a registered partnership and Household Members, the number of people living in the same household as the interviewed individual. Indeed, being married or having a large family might act as a hedge for background financial and health risks if home production and

\footnotetext{
1 We also tested the less intuitive interactions Wealth *Health Background Risk and Health * Financial Background Risk but they were not significant at the standard confidence intervals.

${ }^{2}$ In appendix A.1., we show in the Expected Utility framework the equivalence between these two interpretations of the interaction terms.
} 
market production are substitutes (Edwards, 2008). We add whether the individual is working or unemployed/retired as labour income could also be interpreted as a hedge against financial risk (see e.g. Janaghan and Kocherlakota 1996; Viceira, 2001). Besides, we include in the specification the series of risky behaviours addressed earlier that influence health risk, i.e. the probability of having a future disease. Drinking is defined as having drunk more than two glasses at least once in the last month. Physical Activity is defined as performing a vigorous physical activity at least once a month and Overweight as having a BMI greater than 30 . Finally we have considered country dummies.

\subsection{Descriptive statistics}

Table 1 reports descriptive statistics for the variables used in the empirical analysis.

Table 1

Descriptive statistics ${ }^{\mathrm{a}}$

\begin{tabular}{|c|c|c|c|c|}
\hline Variable & $\begin{array}{l}\text { Mean } \\
\text { (all) }\end{array}$ & $\begin{array}{l}\text { Standard } \\
\text { deviation }\end{array}$ & Minimum & Maximum \\
\hline \multicolumn{5}{|l|}{ Dependent variable } \\
\hline Financial risk Aversion & 3.719 & 0.553 & 1 & 4 \\
\hline \multicolumn{5}{|l|}{ Independent variables } \\
\hline Financial Wealth (in '000 €) & 77.124 & $1^{\prime} 610.277$ & 0 & $120^{\prime} 000$ \\
\hline Annual Income (in '000 €) & 51.905 & $1 ’ 785.055$ & 0 & $150 ’ 000$ \\
\hline Financial background Risk & 0.199 & 0.399 & 0 & 1 \\
\hline Self-Reported health & 2.757 & 1.055 & 1 & 5 \\
\hline Health background Risk & 0.123 & 0.329 & 0 & 1 \\
\hline Smoking & 0.183 & 0.387 & 0 & 1 \\
\hline Drinking & 0.205 & 0.404 & 0 & 1 \\
\hline Overweight & 0.226 & 0.418 & 0 & 1 \\
\hline Physical Exercise & 0.569 & 0.495 & 0 & 1 \\
\hline Self Employed & 0.034 & 0.182 & 0 & 1 \\
\hline Gender & 0.560 & 0.496 & 0 & 1 \\
\hline Age & 67.805 & 32.117 & 22 & 102 \\
\hline Height (in cm) & 168.242 & 9.285 & 72 & 204 \\
\hline Parental Education & 4.016 & 2.059 & 1 & 15 \\
\hline Cognitive Ability & 6.069 & 2.078 & 0 & 10 \\
\hline Married & 0.694 & 0.461 & 0 & 1 \\
\hline Household Members & 2.069 & 0.911 & 1 & 11 \\
\hline Active & 0.126 & 0.332 & 0 & 1 \\
\hline
\end{tabular}

${ }^{a}$ Number of observations: 24 '281 for all the sample.

\subsection{Econometric approach}

We assume the following empirical relationship between the dependent variable and the explanatory variables for the individual $i$ : 


$$
\begin{gathered}
Y_{i}=\beta_{1} \text { Wealth }_{i}+\beta_{2} \text { Income }_{i}+\beta_{3} \text { FBR }_{i}+\beta_{4} \text { Wealth }_{i} * F B R_{i}+\beta_{5} \text { SRH }_{i}+\beta_{6} \text { HBR }_{i} \\
+\beta_{7} \text { SRH }_{i} * H B R_{i}+X^{\prime}{ }_{1, i} \beta_{8}+X^{\prime}{ }_{2, i} \beta_{9}+C^{\prime}{ }_{i} \beta_{10}+\varepsilon_{i}
\end{gathered}
$$

where Wealth $_{i}$ is the demeaned natural $\log$ of individual $i$ 's financial wealth, Income $_{i}$ the demeaned natural $\log$ of his/her annual income, $F B R_{i}$ a binary variable stating whether the individual faces a financial background risk, $S R H_{i}$ his/her self-reported health status scaled to have zero as the modal answer, $H B R_{i}$ a dummy variable indicating the presence of a health background risk, $X_{1, i}$ a series of behavioral controls (Smoking, Drinking, Overweight and Physical Activity) directly affecting health and health risk and very likely to be correlated with financial risk aversion, $X_{2, i}$ the rest of socio-demographic controls, $C^{\prime}{ }_{i}$ the country dummies, and $\varepsilon_{i}$ an error term assumed to follow the OLS standard assumptions.

\section{Results}

Table 2 presents the results for the OLS estimation.

Table 2

\begin{tabular}{|c|c|}
\hline $\begin{array}{l}\text { Dependent variable: } \\
\text { Financial Risk Aversion }\end{array}$ & $\begin{array}{l}\text { OLS model } \\
\text { (all sample) }\end{array}$ \\
\hline Intercept & $\begin{array}{c}4.318 * * * \\
(0.088)\end{array}$ \\
\hline Wealth & $\begin{array}{c}-0.029 * * * \\
(0.001)\end{array}$ \\
\hline Income & $\begin{aligned}-0.002 \\
(0.002)\end{aligned}$ \\
\hline Financial Background Risk & $\begin{array}{c}0.052 * * * \\
(0.016)\end{array}$ \\
\hline Wealth * Financial Background Risk & $\begin{array}{c}0.012 * * * \\
(0.003)\end{array}$ \\
\hline Self-Reported Health & $\begin{array}{c}-0.016 * * * \\
(0.004)\end{array}$ \\
\hline Health Background Risk & $\begin{array}{c}0.154 * * * \\
(0.058)\end{array}$ \\
\hline Health * Health Background Risk & $\begin{array}{c}-0.037 * * * \\
(0.010)\end{array}$ \\
\hline Smoking & $\begin{array}{l}0.017^{*} \\
(0.009)\end{array}$ \\
\hline Drinking & $\begin{array}{c}-0.050 * * * \\
(0.009)\end{array}$ \\
\hline Overweight & $\begin{array}{l}-0.002 \\
(0.008)\end{array}$ \\
\hline Physical Exercise & $\begin{array}{c}-0.034 * * * \\
(0.007)\end{array}$ \\
\hline Self Employed & $\begin{array}{c}-0.150 * * * \\
(0.019)\end{array}$ \\
\hline Gender & $\begin{array}{c}0.091 * * * \\
(0.009)\end{array}$ \\
\hline Age & $\begin{array}{l}0.000^{*} \\
(0.000)\end{array}$ \\
\hline
\end{tabular}

OLS model containing all the variables 


\begin{tabular}{|c|c|}
\hline Height & $\begin{array}{c}-0.003 * * * \\
(0.000)\end{array}$ \\
\hline Parental Education & $\begin{array}{c}-0.021 * * * \\
(0.002)\end{array}$ \\
\hline Cognitive Ability & $\begin{array}{c}-0.016 * * * \\
(0.002)\end{array}$ \\
\hline Married & $\begin{array}{c}0.031 * * * \\
(0.011)\end{array}$ \\
\hline Household Members & $\begin{array}{r}-0.010 * * \\
(0.005)\end{array}$ \\
\hline Active & $\begin{array}{c}-0.215 * * * \\
(0.057)\end{array}$ \\
\hline Country Dummies & YES \\
\hline Observations & $24 ' 281$ \\
\hline Adjusted $\mathrm{R}^{2}$ & 0.133 \\
\hline
\end{tabular}

\subsection{DARA}

The coefficient corresponding to wealth is negative and highly significant (t-statistic of -20), being the coefficient with the largest t-statistic in the whole regression after the intercept. The coefficient corresponding to income has the expected sign but is not significant at the $10 \%$ level (t-statistic of -1.150). Our first empirical results support the DARA hypothesis.

\subsection{Cross DARA}

Looking at the relationship between health and risk aversion, the self-reported health coefficient is negative and statistically significant (t-statistic of -4.31). This implies that an improvement in health reduces risk aversion keeping everything else constant, supporting the cross-DARA hypothesis.

\subsection{Risk vulnerability}

The coefficient corresponding to risk vulnerability has the expected sign and is highly significant $(\mathrm{t}$-stat $=3.151)$, thereby supporting the risk vulnerability hypothesis.

However, the fact that the coefficient for Self Employed is negative and highly significant highlights the potential problems of endogeneity and self-selection that are very likely to arise in the analysis of the effects of background risk on risk aversion as stressed earlier.

\subsection{Cross risk vulnerability}

The coefficient corresponding to background health risk has the expected positive sign and is statistically significant at the $1 \%$ level, therefore it supports the cross-risk vulnerability hypothesis. Individuals facing an additional health risk are more financially risk-averse, ceteris paribus. 


\subsection{Interaction terms}

The term Wealth * Financial Background Risk is positive and statistically significant (t-stat = 4.235), supporting the initial hypothesis of DARA heterogeneity. Given that the parameter corresponding to wealth is negative (DARA effect) and the parameter corresponding to the background risk is positive (risk vulnerability effect), a positive interaction term indicates that the presence of a financial background risk reduces the magnitude of the DARA effect (i.e. Eq. (1) in Appendix A.1. is negative) and at the same time increases financial risk aversion. Analogously, as shown in Appendix A.1., a positive interaction term indicates that the magnitude of risk vulnerability is relatively larger for wealthy individuals (i.e. Eq. (2) in Appendix A.1. is negative), ceteris paribus.

The term Health * Health Background Risk is negative and statistically significant (t-stat = -3.743), supporting as well the initial hypothesis of cross-DARA heterogeneity. As the parameter corresponding to health is negative (cross-DARA effect) and the parameter corresponding to the background health risk is positive (cross-risk vulnerability effect), thus, contrarily to the previous interaction term, the presence a health background risk increases the magnitude of the cross-DARA effect (i.e. Eq. (3) in Appendix A.1. is positive). Equivalently, unhealthy individuals are more cross-risk vulnerable than healthy individuals as their level of financial risk aversion is more sensitive to the presence of a health background risk (i.e. Eq. (4) in Appendix A.1. is positive), ceteris paribus.

\subsection{Other controls}

The exogenous determinants of risk aversion suggested by Dohmen et al. (2011) have the expected signs and are also highly significant. Women and older people are expected to be more risk-averse while tall individuals, individuals with highly educated parents and people with good results in the test of cognitive ability are less risk-averse on average. An additional household member is related to lower financial risk aversion while being married is related to higher risk aversion. Finally, being active is significantly correlated with lower risk aversion.

Looking at the effects of risky behaviours used by Atella et al. (2011) to define health risks, results are mixed. While drinking is correlated with lower risk aversion, smoking is correlated with higher risk aversion and obesity does not have a statistically significant effect in predicting more financial risk aversion. Also, one of the activities reducing the most health risk, physical activity, is related to lower risk aversion.

\section{Robustness checks}

In this section, we test the robustness of our results. We first discuss the weaknesses and the potential biases of our initial model as well as the appropriate econometric strategies to address these biases. We then present our new results using these new strategies.

\subsection{DARA}

Our first concern with respect to the validity of our results is the potential endogeneity in the variables Wealth and Income coming from a simultaneity bias. Indeed, an increase in financial assets or in income might cause a decrease in risk aversion (DARA property) but the causality 
can go the other way round as well if a decrease in risk aversion increases wealth or income. This happens, for example, via stock returns if those are larger than for safer investments' returns. In that case, the coefficients corresponding to Wealth and Income are biased and are even likely to create biases for all coefficients of variables correlated with income and wealth.

In order to solve this problem, we perform an instrumental variables (IV) strategy. Concretely, we take advantage of the international dimension of the SHARE survey and use Switzerland, a variable equal to one if the surveyed individual lives in Switzerland and equal to zero otherwise, and Overweight as instruments for Wealth. Those variables are likely to be good instruments as their coefficients are not statistically significant in the OLS specification (see Table 2) and thus might plausibly be exogenous. However, they are likely to be correlated with financial wealth. In appendix A.2., we present the first-stage regression showing the relevance of the instruments used and the result of the Hausman (1978) test specification checking the robustness of the OLS estimators. As the Hausman test does not reject the null hypothesis $H_{0}$ : $\beta_{O L S}=\beta_{I V}$, the OLS coefficients are robust and efficient with respect to the IV estimators.

Finally, we drop the variable Income as it is considerably correlated with Wealth $(\rho=0.335)$ and thus very likely to have the same simultaneity bias, as Wealth is not significant at the usual confidence levels.

\subsection{Cross-DARA and cross-risk vulnerability}

Drawbacks of self-reported measures of health have largely been documented in the literature. In particular, Bound et al. (1999) acknowledge measurement bias and self-selection bias. First, as respondents are asked for subjective judgments, those judgments might not be entirely comparable across respondents, leading to the so-called error of measurement bias which tends to underestimate marginal effects. However, looking at the parameters Self-reported health and Health background risk, they both are highly significant, which is inconsistent with the hypothesis of marginal effect underestimation.

Second, concerning self-selection bias, surveyed individuals might have economic incentives to reveal a different level of health in some situations if there are economic advantages (e.g. subsidies) for people with bad health. Also, respondents outside the labour market might rationalize their behaviour by declaring themselves in bad health. However, these issues should not concern surveyed individual of SHARE as first, their reply to the risk aversion question is not conditioned by any economic advantages, and second, it would not make sense that individuals rationalize risk aversion by declaring themselves in bad health.

Finally, it should be stressed that using an objective measure of health such as the number of chronic diseases has other drawbacks. Measurement error could also be present if the aggregate objective measure does not reflect correctly the severity of the respondents' diseases or the worsening in their quality of life. For instance, measurement error bias might be the reason why Attella et al. (2012) find that self-reported health affects stockholding but not an objective measure of health status. Other studies in health economics such as Van Houtven et al. (2015) come to the same conclusion, finding significant effects of self-reported health but not of objective measures of health on their variable of interest.

\subsection{Risk vulnerability, cross-risk vulnerability and the interaction terms}

Self-selection is likely to bias our results if less risk-averse individuals choose to face risky situations. However, as stressed earlier, this bias is unlikely to affect our results as we have controlled both the financial background risk by considering self-employed individuals and the 
health background risk by considering the variables Smoker, Drinking, Overweight and Physical Activity. Additionally, the way we define financial uncertainty and health uncertainty in our specification is not voluntary and thus exogenous. It should also be stressed that in our model, self-selection bias would underestimate, rather than overestimate, the coefficients corresponding to background risks. This would contradict our results which show positive and highly significant background risk coefficients.

Regarding the interaction terms, while they allow to control the heterogeneity of our sample, they could face multicollinearity as we interact binary variables with wealth and health which are always positive in the definition provided by SHARE. In order to minimize multicollinearity in the explanatory variables, we demeaned the variables Wealth and Income in the first regression (see Table 2) and we redefined the variable Self-Reported Health by scaling it to have zero as the modal answer.

\subsection{Instrumental variable strategy}

Table 3 provides the results of the instrumental variables (IV) strategy.

Table 3

IV model

\begin{tabular}{lc}
\hline Dependent variable: & IV model \\
Financial Risk Aversion & (all sample) \\
\hline Intercept & $4.366^{* * *}$ \\
& $(0.090)$ \\
Wealth (instrument) & $-0.032^{* * *}$ \\
Financial Background Risk & $(0.006)$ \\
& $0.111^{* * *}$ \\
Wealth (instrument) * Financial Background Risk & $(0.042)$ \\
& $0.031^{* * *}$ \\
Self-Reported Health & $(0.013)$ \\
& $-0.023^{* * *}$ \\
Health Background Risk & $(0.004)$ \\
& $0.048^{* * *}$ \\
Health $*$ Health Background Risk & $(0.018)$ \\
Smoking & $-0.036^{* * *}$ \\
& 0.010 \\
Drinking & $0.042^{* * *}$ \\
& $(0.009)$ \\
Physical Exercise & $-0.051^{* * *}$ \\
& $(0.009)$ \\
Self Employed & $-0.036^{* * *}$ \\
Gender & $(0.007)$ \\
Age & $-0.156^{* * *}$ \\
Height & $(0.019)$ \\
& $0.094^{* * *}$ \\
& $(0.009)$ \\
& 0.000 \\
& $(0.000)$ \\
& $-0.003 * * *$ \\
& $(0.000)$
\end{tabular}




\begin{tabular}{lc} 
Parental Education & $-0.024 * * *$ \\
Cognitive Ability & $(0.002)$ \\
& $-0.020 * * *$ \\
Married & $(0.002)$ \\
& 0.009 \\
Household Members & $(0.011)$ \\
& -0.002 \\
Active & 0.005 \\
& $-0.212 * * *$ \\
Country Dummies & $(0.058)$ \\
\hline Observations & YES \\
Adjusted $\mathrm{R}^{2}$ & 24 '281 \\
\hline Country dummies (Austria reference country) included but not reported. Switzerland is \\
excluded of the second stage regression as it is used as an instrument for wealth. \\
Robust standard errors in parentheses. \\
* Significant at 10\%, ** Significant at 5\%, ** Significant at 1\%.
\end{tabular}

The IV approach validates the DARA hypothesis. In the first stage regression, Switzerland and Overweight are jointly highly significant with a F-statistic equals to 587.5. The coefficient corresponding to Wealth instrumented by Switzerland and Overweight still has the expected negative sign and is highly significant. Moreover, the marginal effect of Wealth on financial risk aversion slightly increases; the lower t-statistic being explained by an increase in the coefficient's standard error.

It is interesting to note that the variable Financial Background Risk almost doubles with a tstat much higher. Moreover, the intersection term Wealth (instrument) * Financial Background Risk is also much more important in this specification but with a larger standard error, however still lower than the one corresponding to Wealth. The Hausman test (see appendix A.2.) does not reject the validity of the OLS coefficients corresponding to financial wealth and the interaction term, thus validating the robustness of the results from the OLS specification.

As for the other coefficients, no significant changes are observed. Self-reported health and health background risk still play a significant role in explaining financial risk aversion in our sample as well as the interaction of health with health background risk.

Finally, regarding the controls, the most important changes occur in the variables Age, Married and Household Members which become non-significant at the usual confidence intervals.

\section{Conclusion}

This paper offers an empirical test of the determinants of risk aversion and in particular whether individuals exhibit DARA, cross-DARA, risk vulnerability and cross-risk vulnerability using the SHARE database. Individuals in our sample are found to exhibit DARA, cross-DARA, risk vulnerability and cross risk-vulnerability.

We further show that the magnitude of DARA and cross-DARA depend on the presence of a financial background risk and health background risk respectively, but in opposite directions. In particular, the presence of a financial background risk reduces the intensity of the DARA effect, while the presence of a health background risk increases the intensity of the cross-DARA effect. Such results are also equivalent to have the intensity of risk vulnerability increasing in wealth and the intensity of cross-risk vulnerability decreasing in health. 
These results can offer some valuable recommendations regarding various economic decisions in the face of shocks on health and wealth as they are often driven by risk aversion behaviours with respect to wealth. We provide a few illustrations. For instance, poor people facing risky income should increase less they purchase of insurance than rich people facing the same risk on their income. Those facing health risks in good health should invest less in risky financial assets than those facing the same health risk but in poor health. Marriage and childhood have also been shown to be influenced by risk aversion (Schmidt, 2008); more riskaverse women being less likely to delay marriage and more likely to delay birth or give birth at later ages. So women facing financial risks should marry young and/or give birth at later ages than women facing no financial risk and this should even be more the case for women being in a better financial position.

The results of this paper show that (cross-) risk vulnerability is vulnerable to wealth (health) or equivalently that (cross-) DARA is vulnerable to a (health) wealth risk. Such results call for expanding further theoretical works on risk vulnerability, and in particular to investigate conditions on individual preferences for which indeed (cross-) risk vulnerability is vulnerable to wealth and health. 


\section{References}

Anderson, J.R., Hamal, K.B., 1982. A note on decreasing absolute risk aversion among farmers in Nepal. Australian Journal of Agricultural Economics, 26, 220-225.

Arrow, K.J., 1965. Aspects of the Theory of Risk Bearing. Yrjo Jahnsson Lectures, The Academic Book Store, Helsinki.

Atella, V., Brunetti, M., Maestas, N., 2012. Household Portfolio Choices, health status and health care systems: A cross-country analysis based on SHARE. Journal of Banking and Finance, 36, 1320-1335.

Bertaut, C.C., Haliassos, M., 1995. Why do so few hold stocks? Economic Journal, 105, 11101129.

Börsch-Supan, A., Jürges, H., 2005. The Survey of Health, Ageing and Retirement in Europe. Mannheim Research Institute for the Economics of Ageing, University of Mannheim, Mannheim.

Bonsang, E., Dohmen, T., 2015. Risk attitude and cognitive aging. Journal of Economic Behaviour and Organization, 112, 112-126.

Bound, J. et al., 1999. The dynamic effects of health on the labour force transitions of older workers. Labour Economics, 6, 179-202.

Cardak, B.A., Wilkins, R., 2009. The determinants of household risky asset holdings, Australian evidence on background risk and other factors. Journal of Banking and Finance, 33, 850-860.

Decker, S., Schmitz, H., 2016. Health shocks and risk aversion. Journal of Health and Economics, 50, 156-170.

Dohmen, T. et al., 2011. Individual risk attitudes: Measurement, determinants and behavioural consequences. Journal of the European Economic Association, 9, 522-550.

Edwards, R.J., 2008. Health Risk and Portfolio Choice. Journal of Buisiness \& Economic Statistics, 26, 472-485.

Eisenhauer, J.G., 1997. Risk Aversion, Wealth and the DARA Hypothesis: A New Test. International Advances in Economic Research. 1, 46-53.

Fratantoni, M.C., 1998. Home ownership and investment in risky assets. Journal of Urban Economics 44, 27-42.

Goldman, D.P., Maestas, N., 2013. Medical Expenditure Risk and Household Portolio Choice. Journal of Applied Econometrics, 28, 527-550.

Gollier, C., Pratt J.W., 1996. Risk Vulnerability and the Tempering Effect of Background Risk. Econometrica, 64, 1109-1123.

Greene, W. 2005. Econometric Analysis, $5^{\text {th }}$ edition. Pearson Education France. 77-81.

Guiso, L., Paiella, M., 2008. Risk Aversion, Wealth and Background Risk. Journal of the European Economic Association, 6, 1109-1150.

Guiso, L., Jappelli, T., Terlizzese, D., 1996. Income Risk, Borrowing Constraints and Portfolio Choice. The American Economic Review, 86, 158-172.

Guiso, L., Jappelli, T., Pistaferri, L., 2002. An Empirical Analysis of Earnings and Employment Risk. Journal of Business and Economic Statistics, 20, 241-253.

Hausman, J. 1978. Specification Tests in Econometrics. Econometrica, 46, 1251-1271.

Hochguertel, S., 2003. Precautionary motives and portfolio decisions. Journal of Applied Econometrics, 18, 61-77.

Jagannathan, R., Kocherlakota N.R., 1996. Why should older people invest less in stocks than younger people? Federal Reserve Bank of Minneapolis Quarterly Review, 20, 11-23. 
Levy, H., 1994. Absolute and relative risk aversion: An experimental study. Journal of Risk and Uncertainty, 8, 289-307.

Love, D.A., Smith, P.A., 2010. Does health affect Portfolio choices? Health Economics, 19, 1441-1460.

Malevergne, Y., Rey, B., 2009. On cross-risk vulnerability. Insurance: Mathematics and Economics, 45, 224-229.

Pratt, J.W., 1964. Risk Aversion in the Small and the Large. Econometrica, 32, 122-136.

Rosen, H.S., Wu, S., 2004. Portfolio choice and health status. Journal of Financial Economics, $72,457-484$.

Schurer, S., 2015. Lifecycle patterns in the socioeconomic gradient of risk preferences. Journal of Economic Behavior \& Organization, 119, 482-495

Viceira, L.M., 2001. Optimal portfolio choice for long-horizon investors with nontradable labour income. Journal of Finance, 56, 433-470.

World Health Organization, 2009. Global Health Risks: Mortality and burden of disease attributable to selected major risks. Geneva, World Health Organization.

World Health Organization, 2013. A global brief on hypertension: Silent killer, global public health crisis. Available from: http://thehealthwell.info/node/466541 


\section{Appendix}

A.1. Proof of the equivalence between the two interpretations of the interaction terms

Let us denote $A(w, h)=-\frac{u_{11}(w, h)}{u_{11}(w, h)}$ the absolute financial risk aversion index with $w$ representing wealth and $h$ health.

Let us define $R((w, h) ;(x, y))=A(w+x, h+y)-A(w, h)$.

DARA is equivalent to $R((w, h) ;(-\epsilon, 0))>0$ for all $\epsilon>0$.

Risk vulnerability is equivalent to $R((w, h) ;(\tilde{\theta}, 0))>0$ for all $\tilde{\theta}$ such that $E(\tilde{\theta})<0$.

Sensitivity of DARA to the introduction of a financial background risk writes as

$R((w+\tilde{\theta}, h) ;(-\epsilon, 0))-R((w, h) ;(-\epsilon, 0))=(E[A(w+\tilde{\theta}-\epsilon, h)]-E[A(w+\tilde{\theta}, h)])-$ $(A(w-\epsilon, h)-A(w, h))$

Sensitivity of risk vulnerability to the introduction of a financial loss writes as

$$
\begin{aligned}
& R((w-\epsilon, h) ;(\tilde{\theta}, 0))-R((w, h) ;(\tilde{\theta}, 0))=(E[A(w+\tilde{\theta}-\epsilon, h)]-A(w-\epsilon, h))- \\
& (E[A(w+\tilde{\theta}, h)])-A(w, h))
\end{aligned}
$$

Eqs. (1) and (2) are identical.

Cross-DARA is equivalent to $R((w, h) ;(0,-\epsilon))>0$ for all $\epsilon>0$.

Cross-risk vulnerability is equivalent to $R((w, h) ;(0, \tilde{\theta}))>0$ for all $\tilde{\theta}$ such that $E(\tilde{\theta})<0$.

Sensitivity of cross-DARA to the introduction of a health background risk writes as

$$
\begin{aligned}
& R((w, h+\tilde{\theta}) ;(0,-\epsilon))-R((w, h) ;(0,-\epsilon))=(E[A(w, h+\tilde{\theta}-\epsilon)]-E[A(w, h+\tilde{\theta})])- \\
& (A(w, h-\epsilon)-A(w, h))
\end{aligned}
$$

Sensitivity of cross-risk vulnerability to the introduction of a health loss writes as

$$
\begin{aligned}
& R((w, h-\epsilon) ;(0, \tilde{\theta}))-R((w, h) ;(0, \tilde{\theta}))=(E[A(w, h+\tilde{\theta}-\epsilon)]-A(w, h-\epsilon))- \\
& (E[A(w, h+\tilde{\theta})])-A(w, h))
\end{aligned}
$$

Eqs. (3) and (4) are identical. 


\section{A.2. First stage regressions of the IV model}

Table A.2.1

First stage IV model

\begin{tabular}{|c|c|}
\hline $\begin{array}{l}\text { Dependent variable: } \\
\text { Wealth }(\log )\end{array}$ & $\begin{array}{l}\text { IV model } \\
\text { (all sample) }\end{array}$ \\
\hline Intercept & $\begin{array}{c}-3.008 * * * * \\
(0.022)\end{array}$ \\
\hline Switzerland & $\begin{array}{c}2.685^{* * * *} \\
(0.090)\end{array}$ \\
\hline Overweight & $\begin{array}{c}-0.729 * * * \\
(0.045)\end{array}$ \\
\hline Observations & $24^{\prime} 281$ \\
\hline Adjusted $\mathrm{R}^{2}$ & 0.046 \\
\hline F-statistic & 587.477 \\
\hline
\end{tabular}

Table A.2.2

Hausman specification test

The Hausman specification test is used to compare the OLS and the IV estimators. We can test the null hypothesis that $b_{O L S}$ and $b_{I V}$ are convergent estimators of $\beta$ by looking at the difference $d=b_{I V}-$ $b_{O L S}$ and its variance. Concretely $H=d^{\prime}\{\text { As.Est. } \operatorname{Var}(d)\}^{-1} d$ where $\{$ As.Est.Var $(d)\}=$ $\left\{\right.$ As. Est. $\operatorname{Var}\left(b_{I V}\right)-A s$. Est. $\left.\operatorname{Var}\left(b_{O L S}\right)\right\}$ is an asymptotically distributed chi-squared variable. The number of degrees of freedom depends on the context.

\begin{tabular}{lccccc}
\hline & Estimate & Std. Error & Difference & $\begin{array}{c}\text { Hausman } \\
\text { Statistic }(H)\end{array}$ & $1-X_{2}^{2}(H)$ \\
\hline Wealth & -0.029 & 0.001 & 0.003 & 0.161 & 0.922 \\
Wealth (inst.) & -0.032 & 0.006 & & & \\
Wealth * Background Risk & 0.012 & 0.003 & 0.019 & 2.162 & 0.339 \\
Wealth (inst.) * Background Risk & 0.031 & 0.013 & & & \\
\hline
\end{tabular}

As the different Hausman statistics are below the critical value, we cannot reject the null hypothesis $H_{0}: \beta_{O L S}=\beta_{O L S}$. 